\title{
Some Aspects of the Physics of Gas Flow in the Respiratory System
}

\author{
Martin Grigor Abrahamyan 1, 2 \\ ${ }^{1}$ Department of Physics, Yerevan State University, Yerevan, Armenia \\ ${ }^{2}$ Department of Medicine, Yerevan "Haybusak" University, Yerevan, Armenia
}

\section{Email address:}

martin.abrahamyan@ysu.am

\section{To cite this article:}

Martin Grigor Abrahamyan. Some Aspects of the Physics of Gas Flow in the Respiratory System. International Journal of Clinical and Experimental Medical Sciences. Vol. 4, No. 1, 2018, pp. 1-4. doi: 10.11648/j.ijcems.20180401.11

Received: November 27, 2017; Accepted: December 14, 2017; Published: January 8, 2018

\begin{abstract}
The dynamics and thermodynamics of gas flow in human respiratory system is discussed. Approximating the time dependence change of intrapulmonal pressure in a harmonic law the characteristic timescales for breathing process, as well as the work and the heat loss rate by respiratory system are estimated. The role of surfactants in breathing of warm-blooded and cold-blooded animals is discussed.
\end{abstract}

Keywords: Lung, Breathing, Alveoli, Compliance, Pressure, Surfactant

\section{Introduction}

Main purpose of the respiratory system is to transport oxygen $\mathrm{O}_{2}$ from the outer environment into the blood stream and supply the body with the necessary fuel for the oxidization processes. Second purpose is to remove the rest product of the oxidization process $\mathrm{CO}_{2}$ from the blood and exhale it to the outer environment. Different transport mechanisms are utilized for this purpose; however, all these transport mechanisms are based on pressure differences in the respiratory system [1-3].

The transport of the $\mathrm{CO}_{2}$ takes place by identical processes in reverse direction. Both processes take place at the same time, therefore pressure differences have to be adopted to optimize the transport mechanism.

The inhaled air is a gas mixture of $\sim 80 \% \mathrm{~N}_{2}$ and $20 \% \mathrm{O}_{2}$. The exhaled air is $\sim 80 \% \mathrm{~N}_{2}, 16 \% \mathrm{O}_{2}$, and $4 \% \mathrm{CO}_{2} .1 \%$ oxygen is absorbed and exchanged with carbon dioxide.

The average human being breathes $\sim 6$ liter $/ \mathrm{min}=$ $7.7 \mathrm{~g} / \mathrm{min}$ of air [4-6].

The airways are divided into several sections, to filter, clean and distribute the air: nose - warms and filters the air, mouth - bypass for rapid breathing, trachea - windpipe divides into two, and bronchia - subdivides fifteen times into bronchioles terminated by alveoli with large surface area.

\section{Pressure and Volume of the Lungs}

The process of breathing (respiration) is divided into two distinct phases, inspiration (inhalation) and expiration (exhalation). During inspiration, the diaphragm contracts and pulls downward while the muscles between the ribs contract and pull upward. This increases the size of the thoracic cavity and decreases the pressure inside. As a result, air rushes in and fills the lungs.

The breathing is controlled by the pressure volume conditions in the lungs.

Lungs and chest wall are coupled together; lungs are sitting inside the chest in an airtight system. Pressure between lungs and chest wall is called intrapleural or intrathoracic pressure, typically negative with respect to pressure inside the lung.

Pressure changes are coupled by the change of the volume of the lung. The relation is nearly linear and is limited by the elasticity of the lung tissue. A measure of the elasticity of the respiratory system is the compliance. The compliance is determined by the ability of the pressure in the lung system of changing the volume:

$$
C=\mathrm{dV} / \mathrm{dP} \text {. }
$$

Because of close coupling between lung and thorax, expansion of chest also influences the pressure conditions in 
the intrapleural space, $\mathrm{P}_{\mathrm{T}}$, and in the lung (intrapulmonal pressure) $\mathrm{P}_{\mathrm{LT}}$. Where $\mathrm{P}_{\mathrm{LT}}=\mathrm{P}_{\mathrm{L}}+\mathrm{P}_{\mathrm{T}}$. Corresponding compliances of thorax, lung and lung-thorax system are:

Thorax: $\mathrm{C}_{\mathrm{T}}=\mathrm{dV} / \mathrm{dP}_{\mathrm{T}}$

Lung: $\mathrm{C}_{\mathrm{L}}=\mathrm{dV} / \mathrm{dP}_{\mathrm{L}}$

Lung-thorax system: $\mathrm{C}_{\mathrm{LT}}=\mathrm{d}(\mathrm{V}) / \mathrm{dP}_{\mathrm{LT}}$.

Therefore the connection between these compliances looks like $[7,8]$

$$
1 / \mathrm{C}_{\mathrm{LT}}=1 / \mathrm{C}_{\mathrm{L}}+1 / \mathrm{C}_{\mathrm{T}}
$$

\subsection{Resistance for the Air Passage}

The air flow is proportional to the change of volume per time:

$$
\mathrm{Q}=\mathrm{dV} / \mathrm{dt}
$$

The relation between change of volume and the pressure difference $\Delta \mathrm{P}=\mathrm{P}_{\mathrm{LT}}$ is given by the Poiseuille's law [2, 3], which can be written in a look

$$
\mathrm{Q}=\mathrm{dV} / \mathrm{dt}=\Delta \mathrm{P} / \mathrm{R}
$$

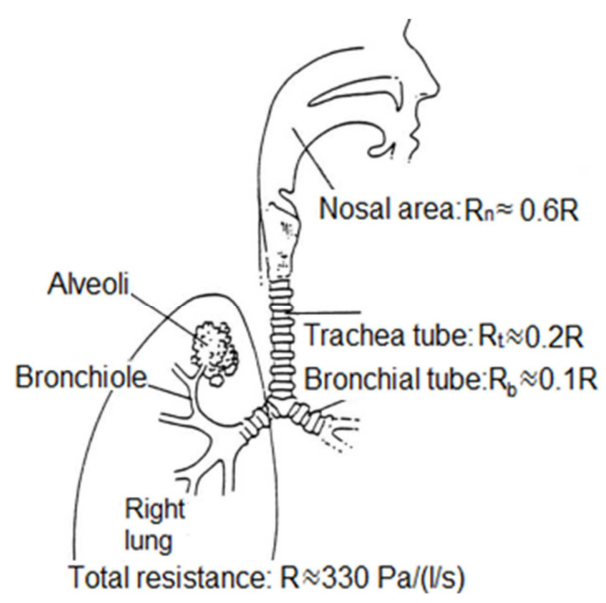

Figure 1. Resistance in the respiratory system.

where $\mathrm{R}$ represents the flow resistance which is determined by the viscosity of air $\eta$, the length $L$ and the radius of the tubes $r$ :

$$
\mathrm{R}=8 \eta \mathrm{L} / \pi \mathrm{r}^{4}
$$

The total resistance is the sum of the single resistances along the air passage

$$
\mathrm{R}=\mathrm{R}_{\mathrm{n}}+\mathrm{R}_{\mathrm{t}}+\mathrm{R}_{\mathrm{b}}
$$

The timescale of the breathing process, in analogue with spring oscillations, depends on the compliance, $\mathrm{C}$, of the respiratory system and on the resistance, $\mathrm{R}$, for the air flow. This follows from that the airflow while inhaling or exhaling, $\mathrm{Q}=\mathrm{dV} / \mathrm{dt}$, is determined by the compliances, $C$, and the resistances, $\mathrm{R}$, in the respiratory system. The airflow can be described as a function of pressure difference $\Delta \mathrm{P}$ and the tidal volume $\Delta \mathrm{V}_{\mathrm{T}}=\mathrm{V}_{\mathrm{VC}}-\mathrm{V}_{\mathrm{FRC}}$

$$
\Delta \mathrm{P}-\mathrm{Q} \cdot \mathrm{R}-\Delta \mathrm{V}_{\mathrm{T}} / C=0 .
$$

At time $\mathrm{t}=0$ lung is at minimum volume, residual capacity: tidal volume: $\Delta \mathrm{V}_{\mathrm{T}} \cong 0$, therefore $\mathrm{Q}=\Delta \mathrm{P} / \mathrm{R}$. This corresponds to the maximum flow intake by the lung.

The rate of change can be determined by differential equation:

$$
\frac{d \Delta P}{d t}-\frac{d Q R}{d t}-\frac{d}{d t} \frac{\Delta V_{T}}{C}=0
$$
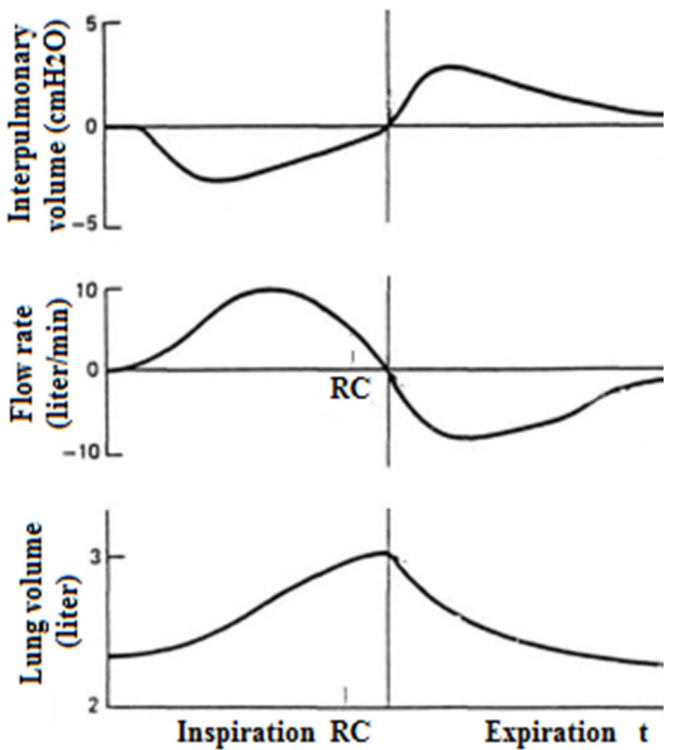

Figure 2. Time dependence of volumes and the flow rate during breathing.

The intrapulmonal pressure $\Delta \mathrm{P}$ shows relatively small changes $\left(-1 \mathrm{~cm} \mathrm{H}_{2} 0\right.$ to $\left.+1 \mathrm{~cm} \mathrm{H}_{2} 0\right)$. Let's to approximate it as follows:

$$
\Delta \mathrm{P}=\mathrm{P}_{0} \cos \pi \mathrm{t} / \mathrm{RC},
$$

where $\mathrm{P}_{0} \approx 1 \mathrm{~cm} \mathrm{H} \mathrm{H}_{2}$.

Taking into account this law in Eq. (7) will have

$$
\frac{d Q}{d t}+\frac{Q}{R C}=\frac{\pi P_{0}}{R^{2} C} \sin \frac{\pi t}{R C}
$$

Solution of this linear, inhomogeneous simple differential equation yields time dependent behavior for flow (breathing rate) and volume:

$$
\begin{aligned}
& Q(t)=\frac{P_{L T}}{R}\left(e^{-t / R C}+\frac{\pi P_{0}}{2 P_{L T}}\left(\operatorname{Cos} \frac{\pi t}{R C}-\operatorname{Sin} \frac{\pi t}{R C}\right)\right), \\
& V(t)=C P_{L T}\left(1-e^{-t / R C}-\frac{\pi P_{0}}{2 P_{L T}}\left(\operatorname{Cos} \frac{\pi t}{R C}-\operatorname{Sin} \frac{\pi t}{R C}\right)\right)
\end{aligned}
$$

The characteristic time of change equals $\mathrm{t}^{*}=\mathrm{R} C$. One breath lasts about:

$$
\mathrm{t}_{\text {breath }} \approx 2 \mathrm{t}^{*}=0.6 \mathrm{~s},
$$

where we used the values: $C \sim 0.001 \mathrm{1} / \mathrm{Pa}$, and for resistance: $\mathrm{R} \approx 300 \mathrm{~Pa} / \mathrm{l} / \mathrm{s}$. 


\subsection{The Heat Loss by the Respiratory System}

Per unit time the heat loss by the respiratory system can be calculated by formula

$$
\Delta \mathrm{Q}=c \cdot\left(\mathrm{t}_{\mathrm{L}}^{\mathrm{o}}-\mathrm{t}^{\mathrm{o}}{ }_{\mathrm{at}}\right) \Delta \mathrm{V}_{\mathrm{T}} / \mathrm{t}_{\text {breath }}
$$

The volume of the exhaled air in an average breath is: $\Delta \mathrm{V}_{\mathrm{T}}$ $\cong 0.4$ liter/breath. Taking into account (8), as well as $\mathrm{t}_{\text {breath }}=0.6 \mathrm{~s}$, and $\mathrm{t}^{\mathrm{o}}{ }_{\mathrm{at}}=21^{\circ} \mathrm{C} ; \mathrm{t}_{\mathrm{L}}^{\mathrm{o}}=37^{\circ} \mathrm{C} ; c \approx 7 \mathrm{cal} / \mathrm{mol}^{\circ} \mathrm{C}$, for $\Delta \mathrm{Q}$, we obtain:

$$
\Delta \mathrm{Q}=2.2 \cdot 10^{-3} \mathrm{kcal} / \mathrm{s} \cong 132 \mathrm{cal} / \text { minute } .
$$

The result depends on the breathing volume and timing.

\subsection{Work Required for Breathing}

The amount of work $A$ necessary to inhale and exhale is described as function of change of the tidal volume [2,9]:

$$
\Delta A=\int_{0}^{\Delta V_{T}} P d \Delta V=\int_{0}^{\Delta V_{T}} \frac{\Delta V}{C} d \Delta V=\frac{\left(\Delta V_{T}\right)^{2}}{2 C}
$$

The rate at which this work is done depends on the number of breaths per unit time, $\mathrm{dn} / \mathrm{dt}$ :

$$
\mathrm{dA} / \mathrm{dt}=\mathrm{A} \cdot \mathrm{dn} / \mathrm{dt} \text {. }
$$

With $\Delta \mathrm{V}_{\mathrm{T}} \approx 2$ liter, $\mathrm{C} \approx 0.1$ liter/ $\mathrm{cmH}_{2} \mathrm{O}, \mathrm{dn} / \mathrm{dt} \approx 10$, we have

$$
\mathrm{dA} / \mathrm{dt}=47 \mathrm{Cal} / \text { minute }
$$

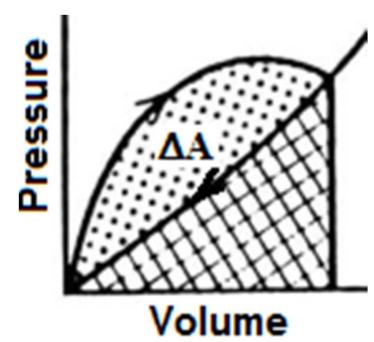

Figure 3. The upper curve on $P, V$ diagram corresponds to inhale process, the lower one - to exhale. The work required for breathing is the area between these curves.

\section{Surfactants and Breathing}

The primary purpose of breathing is to bring atmospheric air into the alveoli where gas exchange with the gases in the blood takes place. The gas exchange takes place by diffusion through the surface membran of the alveoli system. The alveolar small gas bubbles (radius $\sim 0.2 \mathrm{~mm}$ ) at the end of the bronchial system. The lung system has about 100 million alveoli.

Aveoli have a liquid layer between the wall and the air volume. Pressure in the alveoli remains approximately constant. Alveoli are surrounded by capillaric blood vessel system. Separating membran has a thickness of about $0.1 \mu \mathrm{m}$.

The important aspect of breathing is the size of the alveoli. The diameters of the alveoli range from about 0.1 to $0.3 \mathrm{~mm}$. The inner wall of the alveoli is coated with a thin layer of water that protects the tissue. The surface tension of this water layer tends to minimize the surface thereby shrinking the alveolar cavity. When the diaphragm descends, the incoming air has to enter the alveoli and expand them. Expanding the alveoli is analogous to creating a bubble inside a liquid. To create gas bubble of radius $\mathrm{R}$ in a liquid with surface tension $\sigma$, the pressure of the gas in accordance with Laplace formula must be greater than the pressure of the surrounding liquid by $[2,3,10]$

$$
\Delta \mathrm{P}=4 \sigma / \mathrm{R} \text {. }
$$

$\Delta \mathrm{P}$ required to expand a $0.05 \mathrm{~mm}$ diameter alveolus to its full volume is 2.9 atmospheres. This is the minimum pressure required to open alveolus that has its walls coated with plain water. Clearly the incoming air at one atmosphere cannot open the small alveoli and can barely begin to expand the larger ones.

The primary function of lung surfactant is to form monolayers at the alveolar interface capable of lowering the normal surface tension to near zero. To accomplish this process, the surfactant must maintain a coherent, tightly packed monolayer that avoids collapse during expiration. It has been shown that the positively charged amino-terminal peptide sequence SP-B1-25 of lung surfactant-specific protein SP-B increases the collapse pressure of palmitic acid (PA), an important anionic component of lung surfactant, and prevents it from being "squeezed out" from the primarily dipalmitoyl phos phatidyl choline (DPPC) lung surfactant monolayer. However, the mechanisms involved in the alteration of the PA isotherms, and the interactions of lung surfactant specific proteins with PA and other surfactant lipids with low collapse pressures are still not well understood. Utilizing different microscopy techniques, it has been shown that SP-B1-25 inhibits the formation of condensed phases in PA monolayers, resulting in a new fluid PA-protein phase. This fluid phase forms a network that separates condensed phase domains at coexistence [11]. The network persists to high surface pressures, altering the nucleation, growth and morphology of monolayer collapse structures, leading to lower surface tension on compression and more reversible respreading on expansion, factors essential to the in vivo performance of lung surfactant. The network is stabilized by the low line tension between the fluid phase and the condensed phase as confirmed by the formation of extended linear domains or stripe phases. Similar stripes are found in monolayers of fluoresceinlabeled SP-B1-25, suggesting the reduction in line tension be due to the protein. We have also observed that SP-B1-25 in simple phospholipid and model lung surfactant monolayers promote the protrusion of folds into the sub phase at low surface tensions.

Therefore breathing is made possible by surfactants that cover the alveolar water layer and greatly reduce its surface tension. These surfactant molecules are a complex mixture of lipids and proteins produced by special cells in the alveoli and they can reduce surface tension by as much as a factor of 70 (to about $1 \mathrm{dyn} / \mathrm{cm}$ ). 
From the foregoing we conclude that

1. Surface tension in alveoli $\rightarrow$ collapses alveolus

2. Inhaling pressure $(200 \mathrm{~Pa}) \rightarrow$ expands alveolus

3. Stability requires $4 \sigma / \mathrm{R}<200 \mathrm{~Pa}$

4. Surfactant stabilizes alveoli.

The lungs of premature infants often fail to produce adequate amounts of surfactants required for breathing. This life threatening condition called Infant Respiratory Distress Syndrome can now be treated with artificial lung surfactants developed in the 1980s. When introduced into the lungs of the infant these surfactants often stabilize breathing till the alveoli begin to produce surfactants on their own.

Cold-blooded animals such as frogs, snakes and lizards do not need lung surfactants for breathing. Such animals do not use energy to heat their bodies. As a result they require about a factor of ten less oxygen than warm-blooded animals of comparable size. Therefore, cold-blooded animals can function with correspondingly smaller lung surface area. The alveolar radii of these animals are ten times larger than those of warm-blooded animals. An alveolus of larger radius requires correspondingly lower pressure to overcome surface tension eliminating the need for lung surfactants.

\section{Discussion}

During breathing, the body directs the flow of oxygen and nitrogen via coordinated motion of the diaphragm and lungs. In particular, during inhalation the diaphragm muscles are used to increase the volume of the lungs, leading to air intake in a manner analogous to the operation of a piston. During exhalation, the diaphragm muscles undergo an almost-reverse process, decreasing the volume of the lungs and pushing air back out of the body. During inhalation, the alveoli, capillary-rich terminals of pulmonary veins, expand as well, increasing the surface area of the capillary-air interface in order to more effectively accept oxygen into the bloodstream. The key mechanism by which this process occurs is gaseous diffusion, in which carbon dioxide diffuses out of deoxygenated blood through a thin membrane, while oxygen diffuses into the blood. This process is aided by the high solubility of carbon dioxide in blood, which is nearly 20 times that of oxygen $[3,12]$.

The dynamics of the repeated expansion and contraction of the alveoli during respiration are governed by the control of pressure provided by the diaphragm and the elastic response of the alveoli, which passively contract during exhalation without the need for active muscle stimulation. Rather, the diaphragm serves to actively modulate the pressure within the respiratory system, the lungs serve to transmit these pressure differences to the alveoli, and the alveoli respond to these pressure changes in a manner analogous to balloons. Chronic emphysema occurs when the tissues comprising the alveoli lose their elasticity, resulting in incomplete re-compression during exhalation that manifests as labored breathing.

\section{Conclusion}

Simple physical considerations, with the use of equations of Gas dynamics, Molecular physics and Thermodynamics allow us to explain the main regularities of the processes occurring during breathing and to estimate its main characteristics.

\section{Acknowledgements}

I express my gratitude to the referee for useful comments.

\section{References}

[1] Abe T, Sato J, Romero P, Bates JH. Gas physical properties and respiratory system resistance measured by flow interruption. Respir. Physiol. 84 (2): 159-70, 1991.

[2] Abrahamyan M. The Course of Medical \& Biological Physics, LAP, Germany, 2016, 210p.

[3] Davidovits P. Physics in Biology and Medicine, Academic Press, Elsevier, 2012, 352p.

[4] Jerath, R., Edry J. W, Barnes, V. A., Jerath, V., Physiology of long pranayamic breathing, Medical Hypothesis, 67, 566-571, 2006.

[5] Krichkov A, Shnaybel O. Biophysics. Human being energy carriers, Part VI. Physics of the human breathing, M.: Publishing House "Sputnik+", 2015.

[6] Levitzky, M. G. Pulmonary physiology. New York: McGrawHill Medical. p. Chapter 1. Function and Structure of the Respiratory System. ISBN 978-0-07-179313-1. 2013.

[7] Lu W., Neuner G. A., George R., Wang Z., Sasor S., Huang X., Regine W. F., Feigenberg S. J., D’Souza W. D., Int. J. Radiat. Oncol., Biol., Phys. 88, 229-235, 2014.

[8] McKenzie E., Yang W., Burnison M., Mirhadi A., Hakimian B., Stephen S., Robert R., Yue Y., Sandler H., Fraass B., Med. Phys. 41, 474, 2014.

[9] Pollock, Keall, and Keall: Systematic review of breathing guidance studies, Medical Physics, Vol. 42, No. 9, September 2015.

[10] Swami Saradananda, The Power of Breath, Castle House: Duncan Baird Publishers, 2009.

[11] Lee Ka Yee C., The physics of breathing, in: Physics and Biological Systems, New York: McGraw-Hill Medical, 2015.

[12] Steel H., Pollock S., Lee D., Keall P., Kim T., "The internalexternal respiratory motion correlation is unaffected by audiovisual biofeedback,” Australas. Phys. Eng. Sci. Med. 37, 97-102, 2014. 